\title{
Dampak Program Pelaksanaan Pendidikan Sekolah Tinggi Teologi Real Batam Terhadap Pembentukan Karakter Dan Pertumbuhan Iman Mahasiswa
}

\author{
Desy Marnata, ${ }^{* 1}$ Inawati Budiono, ${ }^{2}$ Ester Lina Situmorang ${ }^{3}$ \\ Prodi PAK, STT Real Batam Batam \\ Prodi PAK, STT Real Batam Batam \\ Prodi PAK, STT Real Batam Batam \\ thesymaranataharefa@gmail.com
}

\begin{abstract}
The problem in this research is students who do not have character in words, attitude, behavior, undisciplined, and violate the rules set by the campus. Aside from character, the growth of students' faith in the fear of God does not become a basis for students to truly do God's will. With the rules that have been set, there are still violations committed such as smoking, watching pornography sites, not obeying the rules even to maintain holiness. As an educational institution that is the Real Batam theological high school will do anything to shape the character of students who are not good, and build the growth of their faith to fear the Lord Jesus. Therefore STT Real Batam formed a program that can train them in improving their character and building their faith growth through activities that have a good impact on each student especially the regular class. The impact of Real Batam's theology high school education implementation program has a significant effect on the formation of character and faith growth of students with the average obtained on the variables xl, $y 1$, and $y 2$ namely: the average on the $x 1$ variable gets a mean value of 74.88 , the average variable $y 1$ is 74.45 , and the average yield on variable y2 is 75.57. The research methodology carried out in this paper is quantitative research in the form of statistics and instrument values through SPPSS.

Keywords: Programs, Education, Character Building, Faith Growth, Students
\end{abstract}

\begin{abstract}
Abstrak
Masalah yang ada dalam penelitian ini adalah mahasiswa yang tidak memiliki karaker dalam perkataan, sikap, tingkahlaku, tidak disiplin, dan melanggar peraturan yang telah ditetapkan oleh pihak kampus. Selain dari karakter, pertumbuhan iman mahasiswa untuk takut akan Tuhan tidak menjadi dasar bagi mahasiswa untuk sungguh-sungguh melakukan kehendak Tuhan. Dengan adanya peraturan yang telah ditetapkan, masih saja ada pelanggaran yang dilakukan seperti, merokok, menonton situs pornografi, tidak mematuhi peraturan bahkan untuk menjaga kekudusan. Sebagai Lembaga pendidikan yaitu sekolah tinggi teologi Real Batam akan melakukan apa saja untuk membentuk karakter mahasiswa yang tidak baik, dan membangun pertumbuhan iman mereka untuk takut akan Tuhan Yesus. Oleh sebab itu STT Real Batam membentuk program yang dapat melatih mereka dalam memperbaiki karakter dan membangun pertumbuhan iman mereka melalui kegiatan-kegiatan yang berdampak baik bagi setiap mahasiswa terhusunya kelas reguler. Dampak program pelaksanaan pendidikan sekolah tinggi teologi Real Batam berpengaruh signifikan terhadap pembentukan karakter dan pertumbuhan iman mahasiswa dengan rata-rata yang diperoleh pada variabel $\mathrm{x} 1, \mathrm{y} 1$, dan y2 yaitu: rata-rata pada variabel $\mathrm{x} 1$ memperoleh nilai mean74.88, rata-rata pada variabel y1 sejumlah 74.45, dan hasil rata-rata pada variabel y2 sejumlah 75.57. Metodologi penelitian yang dilakukan dalam penulisan ini adalah penelitian Kuantitatif dalam bentuk statistic dan nilain instrument melalui SPPSS.

Kata kunci: Program, Pendidikan, Pembentukan Karakter, Pertumbuhan Iman, Mahasiswa
\end{abstract}




\section{PENDAHULUAN}

Sekolah Tinggi Teologi Batam (STT Real Batam) merupakan sebuah lembaga pendidikan tinggi Kristen swasta yang ada di kota Batam sejak tahun 2009. Hingga saat ini STT Real Batam mahasiswa-mahasiswa yang berbeda-beda suku dan budaya, dari berbagai tempat yang jauh kepedalaman sampai yang tinggal dikota. Di STT Real Batam mahasiswa diajar untuk membangun iman kepada Tuhan Yesus dimana mereka akan dipersiapkan muntuk menjadi seorang guru, pendeta dan terjun dalam dunia misi untuk menyampaikan injil keberbagai daerah. Selain itu dalam sisi kerohanian, mahasiswa dilatih untuk belajar menjadi seorang pelayan yang takut akan Tuhan, mengubah setiap karakter mereka yang tidak baik, dan belajar untuk menjadi pemimpin dalam pelayanan. Mahasiswa memiliki waktu weekend setiap minggunya. Mereka diharuskan untuk bisa memimpin ibadah, menyampaikan Firman Tuhan, baik itu ibadah komsel maupun dalam ibadah lainnya. Adapun masalah yang terjadi dalam kehidupan mahasiswa adalah kurangnya rasa menghargai. Baik itu menghargai dosen, menghargai yang usianya diatas mereka, maupun menghargai adanya kesenioritasan. Melalui masalah ini seorang siswa yang memasuki perguruan tinggi khususnya mereka yang terpilih untuk menjadi mahasiswa sekolah tinggi teologi Real Batam akan diawasi dan akan diajar dengan penuh Tanggung jawab.untuk hal in terutama kepada mahasiswa kelas reguler akan tinggal diasrama. Oleh sebab itu sikap, tingkahlaku mereka akan terus diawasi, baik itu dalam kampus maupun asrama. Mahasiswa memiliki aturan untuk tidak berbuat sesuka hati mereka. Mahasiswa yang memiliki latar belakang karakter yang buruk akan didampingi untuk memberi pengertian serta melatih mereka untuk mimiliki karakter yang baik.

Selain dari masalah karakter mahasiswa, iman mereka kepada Tuhan untuk memiliki sifat yang takut akan Tuhan dan melayani Tuhan dengan sepenuh hati masih terbatas. Ada pun mahasiswa ketika dalam pelayanan didak dapat menguasai diri dari berbagia hal-hal yang berbaur dengan duniawi, seperti merokok, menonton film pornografi, pergaulan mereka dengan masyarakat sekitar, dan hal buruk lainnya. Seorang mahasiswa teologi, hal yang penting dalam kehidupan mereka adalah iman mereka kepada Tuhan Yesus yaitu percaya dan takut akan Tuhan. Hal ini terjadi karena adanya perbedaan latar belakang kehidupan mahasiswa yang berbeda-beda, pendidikan yang berbeda-beda, dan didikan keluarga yang berbeda-beda. Selain dari itu hal ini pun terjadi karena tidak adanya motivasi dalam diri mahasiswa untuk sungguh-sungguh mau dibentuk, masih keras dengan keinginan sendiri tanpa memikirkan hal buruk yang akan mereka terima, kuliah hanya sebagai rutinitas yang mereka jalani setiap harinya tanpa mengerti tujuan untuk menjadi hamba Tuhan yang siap melayani dan dipakai Tuhan ditempat dimana mereka akan di utus, baik itu dalam pelayanan, pekerjaan, dan juga dalam keluarga. Dari latar belakang masalah diatas, Lembaga kampus perlu memberikan suatu kegiatan positif sehingga mahasiswa melupakan keinginan daging mereka terutam, merokok, minum-minuman keras, bahkan malakukan hal-hal yang berbaur negatif. Untuk memenuh hal tersebut sekolah tinggi 
teologi Real batam membentuk beberapa program yang akan diikuti oleh semua mahasiswa kelas rguler. Dengan adanya kegiatan-kegiatan dalam kampus maupun asrama akan melatih mahasiswa untuk terbaiasa hidup tertib. Dalam hal ini khusunya mereka akan belajar dan memperbaiki karakter mereka serta ada kesadaran untuk bisa berubah.disamping itu mahasiswa juga akan dilative untuk terbiasa membangun hubungan mereka kepada Tuhan Yesus, melalui kegiatan-kegiatan rohani yang telah dirancang. Setiap Lembaga kampus pastinya memilki masalah terutama pada mahasiswa. Akan tetapi mahasiswa yang terpilih menjadi hamba Tuhan dan melayani Tuhan perlu memiliki karakter yang baik dan iman yang bertumbuh kepada Tuhan Yesus. Karena mahasiswa yang akan dipilih untuk melayani harus menjadi berkat bagi lingkungan mereka, keluarga dan dimanapun merea ditempatkan untuk pelayanan.

\section{METODE}

Penelitian yang digunakan dalam penelitian ini adalah metode penelitian kuantitatif. Penelitian kuantitatif adalah jenis penelitian yang pada Sudasarnya menggunakan pendekatan deduktif-induktif. Metode ini disebut sebagai metode positivistic kerena berlandaskan pada filsafat positivisme. Metode ini sebagai metode ilmia kerena telah menemui kiaidah-kaidah ilmiah yaitu konkrit/empiris, obyektif, terukur, rasional dan sistematis. Metode ini disebut metode kuantitatif karena data penelitian berupa angkaangka dan analisis menggunakan statistik. ${ }^{1}$ Dalam metode ini, peneliti tidak melakukan intresprestasi terhadap variable yang diteliti, akan tetapi peneliti melanjutkan Penelitian ini dengan menggunakan angket dari data responden yang disebarkan lalu dikumpulkan dan dianalisis. Teknik pengumpulan data pada metode ini yaitu : metode observasi, angket atau kuesioner dan studi literatur.

\section{HASIL DAN PEMBAHASAN}

\section{Pembentukan Karakter Bagi Mahasiswa}

Pembentukan karakter tidak terlepas dari manfaat karakter itu sendiri, sebab dengan adanya karakter seseorang mampu mengambil keputusan dalam hidupnya sebagai manusia yang bertanggung jawab. Manfaat karakter dalam hidup manusia dapat dijelaskan dalam tiga bagian penting, yaitu sebagai berikut: Bagi Pribadi, Manfaat karakter bagi pribadi sangat menentukan kehidupan kita kepada Kristus. S. H. Widyapranawa mengatakan "jika orang Kristen ingin "mirip seperti Kristus" maka hal itu baru mungkin melalui perubahan radikal dan kehidupan baru". ${ }^{2}$ Artinya, karakter dapat membangun pribadi dengan secara sempurna, yakni sama seperti kehidupan Kristus. Selain itu, juga mencerminkan karakter Kristus di dalam kehidupan pribadi. Dalam Filipi 3:17, berkata "Saudara-saudara, ikutilah teladanku dan perhatikanlah mereka, yang hidup sama seperti kami yang menjadi teladanmu. Artinya, karakter merupakan bukti kedewasaan kita dalam menjalani kehidupan ini. Dan itulah

\footnotetext{
${ }^{1}$ Sugiyono, Metode Penelitian Kuantitatif, Kualitatif Dan $R$ \& D (Bandung: Alfabeta, 2014).100

${ }^{2}$ S H Widyapranawa, Pendidikan Kepribadian Diri Sendiri (Yogyakarta: Taman Pustaka, 2003).112
} 
pentingnya karakter dalam hidup manusia. Jadi, karakter menyatakan siapa Anda dan saya sebenarnya. Bagi Pelayanan: Manfaat karakter bagi pelayanan adalah sebagaimana Rasul Paulus menasihati Timotius bahwa jadilah teladan kepada semua orang dalam segala aspek kehidupanmu (1 Timotius 4:11-16). Artinya, seseorang harus menghidupi apa yang dia ajarkan kepada orang lain. ${ }^{3}$ Untuk dapat melayani dengan baik maka diperlukan karakter-karakter yang mudah ditundukkan kepada Kristus, artinya dalam setiap aspek kehidupan seseorang tersebut mencerminkan seorang pelayan yang baik dan sungguh-sungguh berserah penuh kepada Kristus Dengan demikian, pentingnya karakter dalam hidup manusia menentukan kehidupan manusia itu sendiri. Thomas Lickona mengatakan "karakter kita menentukan bagaimana kita bertindak ketika kita tidak dilihat orang lain. Atau seperti dikatakan pepatah lama, "karakter adalah apa yang anda lakukan saat tidak ada orang yang melihat". Artinya, karakter itu adalah nilai dari kehidupan manusia yang tersembunyi di dalam dirinya namun dapat dinyatakan melalui tindakan yang baik dan benar. Bagi Masyarakat: Manfaat karakter bagi masyarakat adalah jelas seperti yang Tuhan Yesus katakan di dalam Firman-Nya "Kamu adalah garam dan kamu adalah terang" (Matius 5:13-16).Karakter tercermin dalam setiap tindakan-tindakan nyata dalam masyarakat pada umumnya. Artinya, kehidupan kita memberikan dampak kepada masyarakat bukan menjadi batu sandungan.Untuk menyatakan karakter dan kasih Kristus di dalam kehidupan kita, juga dirasakan oleh masyarakat di sekitar kita.Alkitab mengatakan bahwa kamu adalah surat-surat Kristus yang terbuka dan yang dapat dibaca oleh semua orang (2 Korintus 3:1-6).

Pembentukan karakter bagi mahasiswa tidak dapat terpisah dari problem pribadi pribadi mahasiswa itu sendiri. Sekalipun keduanya tidak sama, namun dapat membawa mereka menjadi pribai yang mulia. Karakter seseorang tidak dapat diwariskan dan juga tidak bisa ditukar dengan apapun. Karakter harus dapat dibagun oleh setiap insan terusmenerus malalui suatu proses pendidikan yang berkelanjutan, sehingga setiap orang bertanggung jawab atas karakternya sendiri mampu untuk memiliki kontrol terhadap karakter yang dimilikinya. ${ }^{5}$ Strategi dalam membentuk karakter seseorang tetap menjadi penting dan perlu. ada tiga hal penting yang perlu diperhatikan dalam pembentukan karakter seseorang: pertama; keterampilan, yaitu ada tanggung jawab, keputusan, keindahan, dan lain-lain. Kedua; sikap yang di dalamnya ada sikap bersyukur, watak, takut akan Tuhan, dan ketiga; tata -nilai, yaitu kejujuran, belajar, dan seni.

\section{Pertumbuhan Iman Mahasiswa}

Pertumbuhan iman memberikan dampak nilai-nilai yang dihasilkan oleh iman tersebut bagi setiap orang. Adapun dampak nilai-nilai dari iman itu seperti: dewasa dalam

\footnotetext{
${ }^{3}$ Arozatulo Telaumbanua, "Peranan Guru Pendidikan Agama Kristen Dalam Membentuk Karakter Siswa," FIDEI: Jurnal Teologi Sistematika dan Praktika (2018).

${ }^{4}$ Thomas Lickona, Pendidikan Karakter (Bantul: Kreasi Wacana, 2012). 17

${ }^{5}$ Abu Ahmadi and Nur Uhbiyati, Ilmu Pendidikan (Jakarta: Rineka Cipta, 2002).183
} 
perkataan yaitu orang yang tidak berkata-kata dengan sembarangan (Amsal 17:27-28) dan perkataannya justru menjadi berkat dalam setiap orang yang mendengarnya. Dan apa yang dibicarakannya adalah berbicara sebagaimana mestinya dengan maksud-maksud yang murni atas perintah Allah (2 Kor 2:17), dewasa dalam tindakan yaitu orang yang mampu untuk bertanggung jawab atas dirinya sendiri dan mampu untuk mengambil tindakan dan perbuatannya.

Adapun pertumbuhan iman bagi mahasiswa yaitu, membaca Alkitab dan saat teduh, Kesukaan ini merupakan suatu bukti perubahan dalam dirinya bahwa ia ingin mendekatkan diri kepada Allah dan mendengarkan suara Allah, dan hal ini memberikan kebahagiaan dan kedamaian dalam hatinya yaitu membaca Alkitab dan bersaat teduh (merenungkan Firman Allah).

Beribadah dan bersekutu. Tanggungjawabnya sebagai orang Kristen dengan penuh dedikasi dan komitmen maka ia akan memiliki komitmen untuk mengikuti persekutuan-persekutuan yang selenggarakan gereja seperti persekutuan doa, persekutuan keluarga, dan persekutuan-persekutuan lainnya.

\section{Program Pendidikan Sekolah Tinggi Teologi Real Batam}

Untuk menbangun suatu Lembaga Pendidikan bagi mahasiswa tentunya memiliki program dalam mencapai tujuan. Pengembangan program Pendidikan adalah salah satu cara memajukan mutu pendidikan agar pendidikan memberikan dampak yang baik. ${ }^{6}$ Melalui adanya program pendidikan para mahasiswa tentunya mengerti aktivita apa yang dapat mereka lakukan untuk menambah pengetahuan mereka. Oleh sebab itu adapun tujuan program pendidikan disesuakan dengan apa yang telah dilaksanakan. Pada umumnya tujuan ini dimaksudkan untuk meningkatkan taraf kemampuan pengetahuan, sikap, nilai dan keterampilan, sehingga bisa meningkatkan taraf hidup dan partisipasi dalam membangun dan yang diselenggarakan. ${ }^{7}$ Tujuan ini merupakan titik sentral atau kondisi yang akan dicapai dari pelaksanaan program tersebut.

\section{Masa Orientasi Dan Pembukaan Semester}

Setiap Lembaga kampus memiliki cara tersendiri untuk melakukan kegiatan orientai setiap tahunnya saat pembukaan semester baru bagi mahasiswa baru. STT Real Batam mengadakan masa orientasi mahasiswa dengan tujuan agar mahasiswa yang baru masuk dapat beradaptasi dengan lingkungan dan kehidupan di STT Real Batam. Selain itu, setiap awal semester juga diadakan kebaktian penyegaran rohani dan ceramah khusus untuk memberikan bekal rohani bagi seluruh mahasiswa STT Real Batam Batam. Dalam masa orientasi mahasiwa akan diperlengkapi melalui kegiatan Survival. Kegiatan ini akan

\footnotetext{
${ }^{6}$ Manap Somantri, Perencanaan Pendidikan (Bogor: PT Penerbit IPB Press, 2014).67

${ }^{7}$ Joint Committee, Evaluasi Program, Dan Materi Pendidikan (Semarang: IKIP Semarang Press, 1991). 163
} 
mengajarkan mahasiswa untuk tangguh dan mengenal arti dari pelayanan. Mereka akan dibina, di ajar, dan diperlengkapi melalui kegiatan survival. Dalam kegiatan survival ini mereka diajarkan untuk saling peduli kepada sesama mereka, saling tolong menolong, saling memotivasi, membangun hubungan yang baik kepada kelompok mereka, dan saling membangun iman mereka diantara satu sama lain.

\section{Kebaktian Dan Persekutuan}

Kegiatan kampus maupun asrama setiap harinya juga diisi dengan jadwal kebaktian dan persekutuan doa yang diatur oleh Pembina Asrama agar mahasiswa mempunyai persekutuan dengan Tuhan. Kebaktian/ibadah yang dilakukan mahasiswa selama dikampus yatu, sebelum memulai proses pembelajaran setiap mahasiswa akan melakukan ibadah singkat yang biasa dianamakn ibadah Chapel perkelas. Hal ini dilakukan dengan tujuan untuk melatih mahasiswa agar terbiasa untuk melayani dari kelompok kecil yaitu didalam kelas mereka dan belajar untuk menyampaikan Firman Tuhan didalam kelas sesuai dengan jadwal yang susah disusun oleh seksi kerohanian didalam kelas tersebut. Dengan kegiatan ini akan menumbuhkan iman mahasiswa untuk semakin menganal Tuhan secara pribadi maupun dalam kehidupan mereka. Tidak lepas dari kampus, mahasiswa yang tinggal diasrama juga diperlengkapi dengan kebaktian/ibadah yaitu doa malam dan doa pagi. Asrama juga menjadi hal terpenting untuk membentuk karakter mahasiswa dan pertumbuhan iman mereka dengan kegiatan-kegiatan yang dilakukan diasrama seperti: pedalaman Alkitab (PA), Cerdas Cermat Alkitab (CCA) dan sebagainya.

Selain persekutuan ibadah yang dilakukan di kampus dan diasrama, mahasiswa juga dilibatkan untuk mengisi Menara doa setiap harinya dengan bergantian. Kegiatan ini untuk membiasakan para mahasiswa untuk belajar terlibat dalam persekutuan doa, dan belajar untuk memberikan rasa haus bagi mereka masuk dalam Menara doa.

\section{Pembimbingan}

Untuk menolong mahasiswa dalam menghadapi problem baik menyangkut pergumulan rohani, masalah pribadi dan malasah akademis, Staf Dosen akan memberikan bimbingan kepada mahasiswa baik pribadi maupun berkelompok. mereka akan dibina, diberi pengertian agar mahasiswa dapat menyikapi setiap masalah yang mereka alami dengan positif. Memberikan nasehat kepada mahasiswa agar dikemudian harinya mereka dapat memperbaiki kesalahan dan dapat lebih bijak untuk melakukan segala sesuatunya ketika sudah tidak lagi menjadi mahasiswa dan telah turun untuk melayani masyarakat luas maka pembinaan melalui pembimbingan yang selama ini telah di terima dapat di terapkan dengan sebaik-baiknya dan tetap menjadi pribadi yang sudah dapat menjadi teladan serta mentor bagi orang lain. 


\section{Praktek Mahasiswa / Semester}

STT Real Batam Batam mengkoordinir dan mengarahkan kegiatan pelayanan mahasiswa. Baik pelayanan di kampus dan di luar kampus. Bentuk kegiatan mahasiswa antara lain: setiap pertengahan Juni hingga Agustus ditugaskan belajar dan memperoleh pengalaman melalui Mission Trip keberbagai daerah, melalui pelayanan dua bulan. Selain itu, pada momen-momen tertentu mahasiswa diarahkan untuk melakukan pelayanan sosial ke panti asuhan, lembaga pemasyarakatan, dan lain lain. Hal ini bertujuan agar mahasiswa diajarkan untuk memiliki karakter atau sikap toleransi terhadap sesame bukan hanya dalam lingkungan kampus tetapi juga ketika mahasiswa berada di luar lingkungan kampus. STT Real Batam berusaha untuk memberika pelayanan yang terbaik kepada setiap mahasiswa dengan memberikan kesempatan untuk boleh mengaplikasikan setiap talenta dan kemampuan yang Tuhan berikan dengan cara terlibat dalam setiap kegiatan pelayanan mahasiswa baik itu pada masa liburan semester atau pun pada saat pengutusan sebagai mahasiswa praktek.

\section{Laporan Bulanan}

Untuk mengetahui perkembangan pribadi mahasiswa, dalam kegiatan pelayanan selama sebulan maka semua mahasiswa di wajibkan untuk menyerahkan laporan pelayanan bulanan, terkait kehidupan rohani, pelayanan dan kegiatan akademik. Hasil evaluasi laporan dijadikan acuan untuk membimbing mahasiswa. Laporan pelayanan yang diberikan oleh mahasiswa adalah hasil penilaian dari tempat dimana mereka melayani setiap hari weekend (Jum'at-Minggu). Dengan Laporan pelayanan tersebut karakter dan pertumbuhan iman mahasiswa dapat dilihat dan dinilai oleh para dosen sebagai bahan petimbangan bahwa dari laporan tersebut dan akan menjadi bahan evaluasi bagi para dosen apakah mahasiswa yang di tempat setiap minggu nya di setiap wilayah gereja-gereja mampu untuk memberikan kontribusi yang baik dalam melayani dengan tetap menjunjung tinggi nilai Almamater serta tetap menjaga nama baik lembaga pendidikan STT Real Batam, dengan demikian maka dari laporan pelayanan yang akan di serahkan mahasiswa setiap bulannya akan menjadi dokumen-dokumen yang di arsipkan sebagai dokumen penting untuk dapat menjadi salah satu bukti bahwa setiap mahasiswa dan mahasiswi melakukan bagian mereka dengan baik.

\section{Hasil Uji Korelasi Variabel X dan Variabel Y1,Y2}

Dalam menghitung uji korelasi, akan mendapatkan koefisien korelasi yang memiliki keeratan hubungan antara tiga variable. Untuk nilai koefisien korelasi berkisar antara 0 sampai 1 atau 0 sampai dengan -1. Nilai yang mendekati 1 atau -1 maka hubungan akan semakin erat, jika mendekati 0 maka hubungan semakin lemah. ${ }^{8}$

\footnotetext{
${ }^{8}$ Rochmat Aldy Purnomo, Analisis Statistik Ekonomi Dan Bisnis Dengan SPSS (Untuk Mahasiswa, Dosen Dan Praktisi) (Ponorogo: Wade Group, 2017).137
} 


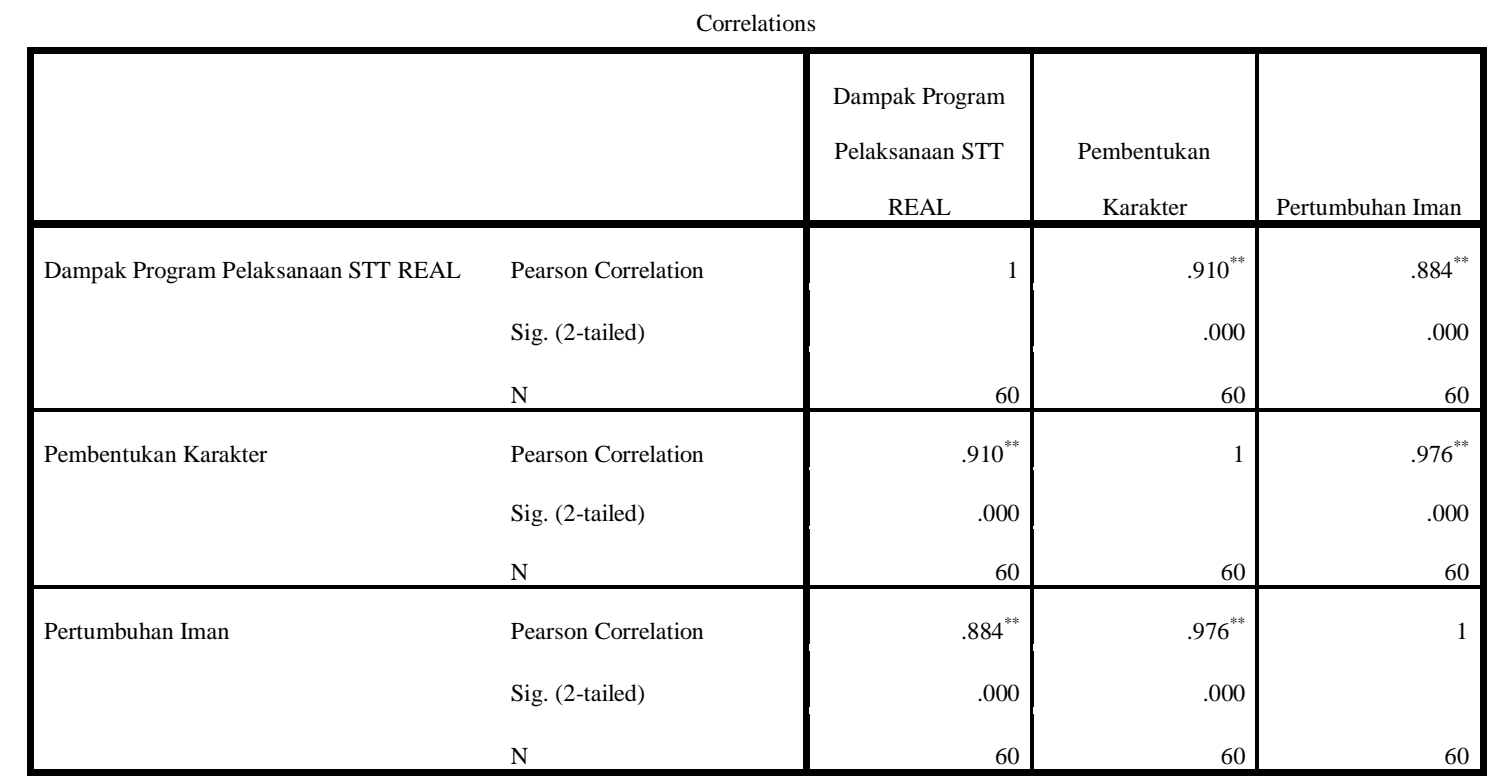

**. Correlation is significant at the 0.01 level (2-tailed).

Berdasarkan hasil uji korelasi variabel $\mathrm{x}$ terhadap variabel y memiliki korelasi yaitu nila variable $\mathrm{X}$ pada $\mathrm{Y} 1$ memiliki nilai korelasi 0,910 dan nilai korelasi variable $\mathrm{X}$ pada Y2 memiliki nilai 0,884. Sedangkan variable x pada y2 memiliki nilai korelasi 0,884. Kemudian untuk nilai signifikasi variable $\mathrm{x}$, y1, y2 yaitu < daripada 0,05. Degan hasil korelasi yang telah diperoleh maka dapat disimplkan bahwa variable $\mathrm{x}$ pada $\mathrm{y} 1$, dan $\mathrm{y} 2$ memiliki hubungan korelasi yang sangat kuat dan bentuk hubungannya adalah positif.

Nilai Rata-rata Variabel X,Y1, Dan Y2

Statistics

VAR X.00001

\begin{tabular}{|l|l|}
\hline Valid & 60 \\
Missing & 0 \\
Mean & 74.88 \\
Median & 76.00 \\
Mode & 78 \\
\hline
\end{tabular}

Statistics

VAR Y.00001

\begin{tabular}{|c|l|}
\hline \multicolumn{1}{|c|}{ Valid } & 60 \\
Missing & 0 \\
Mean & 74.45
\end{tabular}




\begin{tabular}{|l|l|}
\hline Median & 75.00 \\
Mode & 80 \\
\hline Statistics \\
VAR Y.00001 \\
\hline Valid \\
Missing & 56 \\
Mean & 0 \\
Median & 74.57 \\
Mode & 76.00 \\
\hline
\end{tabular}

Tabel Output diatas meberikan penjelasan mengenai $\mathrm{N}$ adalah jumlah data yang valid yaitu 60 mahasiswa, Sedangkan data yang hilang adalah 0 . Artinya semua hasil data mahasiswa diproses ke SPSS. Mean adalah hasil dari nilai rata-rata yang diperoleh pada variabel $\mathrm{x} 1, \mathrm{y} 1$, dan $\mathrm{y} 2$ yaitu: rata-rata pada variabel $\mathrm{x} 1$ memperoleh nilai mean74.88, ratarata pada variabel y1 sejumlah 74.45 , dan hasil rata-rata pada variabel y2 sejumlah 75.57.

\section{KESIMPULAN}

Pola asuh yang seimbang akan selalu menghargai individualitas akan tetapi juga menekankan perlunya aturan dan pengaturan. Mereka dangat percaya diri dalam melakukan pengasuhan tetapi meraka sepenuhnya mengahrgai keputusan yang diambil anak, minat dan pendapat serta perbedaan kepribadiannya. Orang tua dengan pola asuh model ini, penuh dengan cinta kasih, mudah memerinci tetapi menuntut tingkah laku yang baik. Tegas dalam menjaga aturan bersedia memberi hukuman ringan tetapi dalam situasi hangat dan hubungan saling mendukung. Mereka menjelaskan semua tindakan dan hukuman yang mereka lakukan dan minta pendapat anak.

Era globalisasi memang telah mengubah segalanya. Beratnya persaingan hidup telah menyebabkan orang lupa memperhatikan kebutuhn anak karena sibuk mencari nafkah. Sementara perkembangan teknologi informasi dan komunikasi telah menyebabkan budaya luar baik atau buruk mengalir bagitu derasnya. Dampaknya bila tidak ada pengawasan dan bimbingan yang cukup buruk dari luar. Oleh karenanya, sejak dini pada anak perlu ditanamkan nailai-nilai moral sebagai pengatur sikap dan perilaku individu dalam melakukan interaksi sosial di lingkungan keluarga, masyarakat maupun bangsa. Oleh karena itu orang tua mempunyai tugas yang tidak boleh dilalaikan. Orang tua sebagai penuntun dan teladan bagi anak-anak. Tugas orang tua seperti ini merupakan suatu pelayanan yang bertujuan bukan untuk kepentingan anak-anak saja, melainkan terutama untuk memuliakan nama Tuhan.Pemahaman dalam orangtua mengenai pola asuh keluarga Kristen terhadap pertumbuhan iman anak ialah memahami bahwa keluarga merupakan 
wadah utama pertumbuhan iman anak, orang tua harus sering mendidik anak dengan kasih Allah, orangtua harus menjadi teladan bagi anak, orangtua dan anak harus bersama-Sama bertumbuh di Gereja. Pemahaman mengenai konsep maupun pelaksanaan tentang pertumbuhan iman anak adalah pola yang diberikan orang tua dalam mendidik atau mengasuh anak baik secara langsung maupun tidak secara langsung. Cara mendidik secara langsung artinya bentuk asuhan orang tua yang berkaitan dengan pembentukan kepribadian, kecerdasan dan ketrampilan yang dilakukan secara sengaja, baik berupa perintah, larangan, hukuman, penciptaan situasi maupun pemberian hadiah sebagai alat pendidikan.

\section{KEPUSTAKAAN}

Ahmadi, Abu, and Nur Uhbiyati. Ilmu Pendidikan. Jakarta: Rineka Cipta, 2002.

Committee, Joint. Evaluasi Program, Dan Materi Pendidikan. Semarang: IKIP Semarang Press, 1991.

Purnomo, Rochmat Aldy. Analisis Statistik Ekonomi Dan Bisnis Dengan SPSS (Untuk Mahasiswa, Dosen Dan Praktisi). Ponorogo: Wade Group, 2017.

Somantri, Manap. Perencanaan Pendidikan. Bogor: PT Penerbit IPB Press, 2014.

Sugiyono. Metode Penelitian Kuantitatif, Kualitatif Dan R \& D. Bandung: Alfabeta, 2014. Telaumbanua, Arozatulo. "Peranan Guru Pendidikan Agama Kristen Dalam Membentuk Karakter Siswa.” FIDEI: Jurnal Teologi Sistematika dan Praktika (2018).

Thomas Lickona. Pendidikan Karakter. Bantul: Kreasi Wacana, 2012.

Widyapranawa, S H. Pendidikan Kepribadian Diri Sendiri. Yogyakarta: Taman Pustaka, 2003. 